\title{
Plinabulin and Pegfilgrastim in Combination for the Prevention of Chemotherapy-Induced Neutropenia in Patients with Breast Cancer (PROTECTIVE-2): A Randomized Trial
}

\section{Douglas Blayney ( $\sim$ dblayney@stanford.edu )}

Stanford Cancer Institute https://orcid.org/0000-0002-7931-4533

\section{Qingyuan Zhang}

Harbin Medical University Cancer Hospital

\section{Ramon Mohanlal}

BeyondSpring Pharmaceuticals

\section{Lihua Du}

Dalian Wanchuan Bulin Pharmaceuticals Limited

\section{Ene Ette}

Anoixis Corporation

\section{Stephan Ogenstad}

Statogen Consulting, LLC

Hryhoriy Adamchuk

Kryvyi Rig Oncology Dispensary

\section{Tao Sun}

\section{Liaoning Cancer Institute and Hospital}

\section{Hongsheng Li}

Guangxi Cancer Hospital and Guangxi Medical University Affiliated Cancer Hospital

\section{Jifen Feng}

Nanjing Medical University Affiliated Cancer Hospital

\section{Lan Huang}

BeyondSpring Pharmaceuticals

\section{Yuan-kai Shi}

Chinese Academy of Medical Sciences Cancer Institute and Hospital: Cancer Hospital Chinese Academy of Medical Sciences

\section{Research Article}

Keywords: plinabulin, neutropenia, pegfilgrastim, breast cancer, TAC chemotherapy 
Posted Date: January 4th, 2022

DOI: https://doi.org/10.21203/rs.3.rs-1178705/v1

License: (c) (i) This work is licensed under a Creative Commons Attribution 4.0 International License. Read Full License 


\section{Abstract}

\section{Purpose}

Plinabulin is a non-granulocyte colony-stimulating factor (G-CSF) novel small molecule with both anticancer and myeloprotective effects. Single-agent plinabulin is myeloprotective in the first week of the chemotherapy cycle, and pegfilgrastim in the second week. We assessed the efficacy and safety of the combination of plinabulin and pegfilgrastim for the prevention of chemotherapy-induced neutropenia (CIN) following chemotherapy.

\section{Methods}

This randomized, open-label, Phase 2 trial enrolled patients with breast cancer. All received docetaxel 75 $\mathrm{mg} / \mathrm{m}^{2}$, doxorubicin $50 \mathrm{mg} / \mathrm{m}^{2}$, and cyclophosphamide $500 \mathrm{mg} / \mathrm{m}^{2}$ on Day 1 . In the combined therapy cohort, patients received plinabulin $20 \mathrm{mg} / \mathrm{m}^{2}$ on Day 1 and $1.5,3$, or $6 \mathrm{mg}$ pegfilgrastim on Day 2 . The primary objective was to establish the recommended Phase 3 dose (RP3D). Secondary endpoints included absolute neutrophil count (ANC) nadir, relative dose intensity (RDI), and incidence of adverse events including neutropenia and bone pain.

\section{Results}

In total, 115 patients were randomized and evaluated. The combination therapy at the RP3D (plinabulin $20 \mathrm{mg} / \mathrm{m}^{2}$ and pegfilgrastim $6 \mathrm{mg}$ ) was well-tolerated and had superior CIN prevention in terms of Grade 4 and Grade 3/4 neutropenia frequency, absolute neutrophil count (ANC) nadir, higher relative dose intensity (RDI), less bone pain, and less toxicity burden when compared with pegfilgrastim $6 \mathrm{mg}$ alone.

\section{Conclusion}

Plinabulin combined with pegfilgrastim at the RP3D (plinabulin $20 \mathrm{mg} / \mathrm{m}^{2}$ Day 1 and pegfilgrastim $6 \mathrm{mg}$ Day 2) had more favorable efficacy, safety, and tolerability profiles and lower bone pain incidence than did pegfilgrastim alone.

\section{Trial information}

Clinical Trial Registration: ClinicalTrials.gov NCT04227990

Date registered: January 14, 2020

Retrospectively registered

\section{Introduction}

Neutropenia and febrile neutropenia (FN) after myelotoxic chemotherapy are predictive biomarkers for development of infection-related complications - sepsis, antibiotic use, unplanned hospitalization, 
emergency department visits, and death. Use of granulocyte colony-stimulating factor (G-CSF)-based agents can partially prevent these complications [1]. Chemotherapy dose reduction, dose delay, and deferral of further therapy are mitigation strategies [2]. The G-CSFs filgrastim and pegfilgrastim reduce depth and duration of chemotherapyinduced neutropenia (CIN), duration of severe (Grade 4) neutropenia (DSN) from 5.6 days to 2.4 days, and reduce other CIN-related complications[1, 3]. Primary prophylactic G-CSF was recommended for chemotherapy regimens with greater than $20 \%$ risk for FN by the National Comprehensive Cancer Network (NCCN) guidelines until recently, when the risk threshold was lowered to chemotherapy regimens with FN risk of $10-20 \%$ to potentially reduce iatrogenic COVID-19 infection and illness $[4,5]$.

Plinabulin (BPI-2358, formerly NPI-2358) is a non- G-CSF small molecule with anti-cancer activity [6] and when administered with docetaxel chemotherapy, reduces the incidence of severe neutropenia observed with docetaxel alone [7]. In preclinical models, plinabulin alleviated neutropenia induced by microtubule stabilizing, DNA cross-linking, and DNA intercalating chemotherapies, yet did not affect bone marrow or blood G-CSF levels [8]. In a previous clinical trial, we showed that plinabulin mitigates $\mathrm{CIN}$ in the intermediate FN risk setting of docetaxel $75 \mathrm{mg} / \mathrm{m}^{2}[9]$.

The TAC regimen (docetaxel, doxorubicin, and cyclophosphamide) is a standard treatment for early-stage breast cancer [10] and is also used for firstline treatment of patients with metastatic breast cancer [11]. TAC is the chemotherapy regimen used to support regulatory approval of filgrastim [12] and filgrastim biosimilar agents [13-16]. TAC and routine prophylactic G-CSF use has Grade 4 neutropenia incidence of $83-93 \%$ and Grade 3 or 4 neutropenia at $96-100 \%[17,18]$. Consequently, primary GCSF prophylaxis for CIN and FN prevention is standard [3, 4, 12], even though G-CSF prophylaxis does not completely mitigate $\mathrm{CIN}$ after TAC and other high FN-risk chemotherapy regimens. More complete CIN protection is an unmet medical need.

In this dose finding study, we first evaluated single doses of plinabulin to determine the optimal plinabulin dose, that we next combined with three dose levels of pegfilgrastim to treat patients with breast cancer and identify the recommended Phase 3 dose (RP3D) of plinabulin and pegfilgrastim. The rational for combining these two CIN preventive agents was that single-agent plinabulin was myeloprotective in the first week of the chemotherapy cycle, and pegfilgrastim in the second week. The combination could have superior CIN prevention compared to either agent alone.

\section{Methods}

This multicenter, open-label, randomized Phase 2 portion of clinical trial PROTECTIVE-2 (NCT04227990 registered January 14, 2020, BPI-2358-106) enrolled adult women with Stage I, II, or III breast cancer who were candidates for at least four cycles of TAC chemotherapy. Eligible patients did not have previous chemotherapy, had Eastern Cooperative Oncology Group (ECOG) performance status of 0 or 1 with adequate hematologic and organ function, and were recruited from the clinical populations of the study 
centers. Exclusion criteria included concurrent administration of chemotherapy or radiation therapy, active infection, or the use of strong cytochrome P4503A4 inhibitors.

All patients received docetaxel $75 \mathrm{mg} / \mathrm{m}^{2}$, doxorubicin $50 \mathrm{mg} / \mathrm{m}^{2}$, and cyclophosphamide $500 \mathrm{mg} / \mathrm{m}^{2}$ (TAC) on Day 1 by intravenous infusion (IV), repeated every three weeks for four cycles. We evaluated patients in two separate, sequential cohorts with parallel randomization schemes. In the monotherapy cohort, patients were randomized to pegfilgrastim $6 \mathrm{mg}$ by subcutaneous injection (SQ) on Day 2 or plinabulin IV at either 10,20 , or $30 \mathrm{mg} / \mathrm{m}^{2}, 30$ minutes after docetaxel on Day 1 , with no Day 2 treatment. (Online Resource Fig. 1a). Based on the results of the single-agent plinabulin study, a superiority objective would not be met. We amended the protocol to evaluate an additional combined therapy cohort: plinabulin $20 \mathrm{mg} / \mathrm{m}^{2}$ with pegfilgrastim 1.5, 3, or $6 \mathrm{mg}$ on Day 2, compared with monotherapy pegfilgrastim $6 \mathrm{mg}$ (Online Resource Fig. 1b). Randomization was by the Medidata electronic data capture (EDC) system.

Complete blood count and absolute neutrophil count (ANC) were collected during Cycle 1 on Days 1 (predose), $2,3,6,7,8,9,10,11,12,13$, and 15, and during subsequent cycles on Days 1 (predose), 8, and 15, and measured at a central laboratory (Covance, Shanghai and Covance, Geneva). Ambulatory blood pressure (AMBP) was measured at 15minute intervals on Day 1 of Cycle 1 , starting 15 minutes preplinabulin until 3 hours after plinabulin completion.

At investigator discretion, doxorubicin could be omitted (that is, TAC converted to TC) during Cycles 2 through 4 or continued for more than four cycles. Docetaxel premedication with corticosteroids and rescue medications to treat FN was pre-specified.

\subsection{Trial Outcomes}

The primary objective was to establish the recommended Phase 3 dose (RP3D) of plinabulin based on pharmacokinetic (PK) and pharmacodynamic (PD) analyses. The primary efficacy PD endpoint was DSN (Grade 4; defined as ANC $<0.5 \times 10^{9} / \mathrm{L}$ ). The primary safety endpoint was blood pressure on Day 1 of Cycle 1 within 3.5 hours after the docetaxel infusion. PK of plinabulin, pegfilgrastim and the TAC components, and the plinabulin PK and PD for CIN prevention was modeled with a nonlinear mixed effects approach (NONMEM, ICON Development, Ellicott City, MD) using a sequential PK/PD approach for plinabulin CIN prevention. Separate population PK models were developed for plinabulin, docetaxel, doxorubicin, cyclophosphamide, and pegfilgrastim (Online Resource Supplemental Material).

Secondary endpoints included the frequency of patients with at least one day of Grade 4 neutropenia, Grade 3 or 4 neutropenia, ANC nadir, change in bone pain between pretreatment during cycle 1, relative dose intensity, safety, and tolerability. Bone pain was evaluated by using the Brief Pain Inventory[19, 20] before trial drug infusion on Day 1 compared with Days $1-8$ of Cycle 1. Tolerability is defined as the number of patients who received $>85 \%$ of the planned chemotherapy dose. 
Exploratory endpoints included FN incidence, CD34+ stem cell mobilization, health-related quality of life (QOL), and thrombocytopenia. The European Organization for Research and Treatment of Cancer Quality of Life Questionnaire C30 (EORTCQLQ-C30) was used to evaluate QOL [21-23]. Changes from baseline in platelet count were used to investigate the incidence of thrombocytopenia during the trial. The frequency of patients with thrombocytopenia was analyzed for each treatment group in the combined therapy cohort.

\subsection{Statistical Methods}

Patients were stratified by region: China versus the rest of the world. The pegfilgrastim $6 \mathrm{mg}$ monotherapy data served as the comparator arm for both cohorts, and hypotheses testing used a significance level of 0.05 . In the monotherapy cohort, with an $80 \%$ power to detect an event rate ratio of 0.3 and a significance level of 0.05 , up to 18 patients in each arm were required. In the combined therapy cohort, two sequential tests were made by using the O'Brien-Fleming spending function to determine the test boundaries. During an interim analysis, if a statistically significantly superior outcome with respect to DSN was reached when comparing pegfilgrastim alone to any of the combination treatments, or an indication that superiority could not be achieved, then no further patients were allocated to the combination arms.

All randomized patients were included in the intent-to-treat (ITT) analysis set, and the safety analysis set included all randomized patients who received at least one dose of any trial medication. Stata v11.0 or later generalized Poisson model procedures were used to assess Cycle 1 DSN. Barnard's method was used to evaluate the difference in proportions of Grade 4 and Grade 3/4 neutropenia between the treatment arms. For the assessment of bone pain, the mean change from pre-dose (Day 1) bone pain score to Days 2 through 8 in Cycle 1 were analyzed by using repeated measures mixed linear model with the predose (Day 1) value and treatment arm as covariates. The method was used to construct point estimates and confidence intervals (Cls). Post-hoc analyses of mean bone pain score by visit and treatment group were performed by using a repeated measure mixed linear model, with the baseline value and treatment arm as covariates. Continuous variables were summarized with counts, means, standard deviations, medians, Cls, minimums, and maximums. Categorical variables were summarized by counts and by the percentage of patients. Descriptive summaries were also provided. Missing or invalid data were not imputed. The PK/PD modeling approach adopted to estimate the population PK of plinabulin and the TAC drugs and to characterize the plinabulin PK and PD in preventing $\mathrm{CIN}$ is summarized in Online Resource Supplemental Material.

All patients provided written informed consent. The trial was conducted following International Council for Harmonization Good Clinical Practice guidelines and ethical principles and approved by the relevant Independent Ethics Committee or Institutional Review Board at each site. The datasets generated during and/or analyzed during the current study are available from the corresponding author on reasonable request 


\section{Results}

One hundred fifteen patients were treated, 42 in the monotherapy and 51 in the combined therapy cohorts; 22 patients who were concurrently randomized to pegfilgrastim $6 \mathrm{mg}$ were included in both cohorts for comparison purposes. (Fig. 1a, Fig. 1b, Online Resource Fig. 2a, Fig. 2b) Patients were accrued between December 2017 and January 2019 at 9 sites in China and Ukraine. There were no pretreatment demographic differences among the groups. (Online Resource Tables 1a and 1b).

For the primary endpoint - determination of the RP3D - results from all seven treatment arms were evaluated. In the monotherapy cohort, the single agent plinabulin arms were not superior to pegfilgrastim (Table 1a). The ANC recovery curves are illustrated in Fig. 2a, and distribution of the DSN is shown in Online Resource Fig. 3a. Plinabulin's benefit is protecting the ANC during Week 1 after chemotherapy, while pegfilgrastim's protective effect is constant during Week 2. With results from the Phase 2 clinical trial (PROTECTIVE-1) also showing Week $1 \mathrm{CIN}$ prevention in plinabulin monotherapy [9], we modified the study design to include combinations of plinabulin and pegfilgrastim. Plinabulin $20 \mathrm{mg} / \mathrm{m}^{2}$ with pegfilgrastim $6 \mathrm{mg}$ performed best, with a mean DSN in Cycle 1 of 0.69 days vs 0.73 days for pegfilgrastim alone ( $P$ non-significant, Table 1B). The ANC recovery curves for all combination arms are illustrated in Fig. 2b. The DSN distribution for this best performing combination compared with the control is shown in Fig. 2c.

Plinabulin did not have an effect on AMBP, the primary safety objective (see Online Resource Fig. 4).

For the secondary endpoint of frequency of at least one day of Grade 4 neutropenia, $37.5 \%$ of patients receiving plinabulin $20 \mathrm{mg} / \mathrm{m}^{2}$ and pegfilgrastim $6 \mathrm{mg}$ combination had at least one day of Grade 4 neutropenia, compared with $59.1 \%$ for patients receiving pegfilgrastim $6 \mathrm{mg}$ alone (Online Resource Table 4b). For bone pain, patients taking pegfilgrastim $6 \mathrm{mg}$ alone experienced a higher number of days of bone pain than did patients taking combined plinabulin $20 \mathrm{mg} / \mathrm{m}^{2}$ and pegfilgrastim $6 \mathrm{mg}$ (Fig. 2d). For chemotherapy tolerability, $100 \%$ of patients in the plinabulin $20 \mathrm{mg} / \mathrm{m}^{2}$ and pegfilgrastim $6 \mathrm{mg}$ arm were able to receive $>85 \%$ of their planned chemotherapy dose compared with $82 \%$ in the pegfilgrastim alone arm (Table 2a). The relative dose intensity (RDI) also favored the combination arm (0.998 vs 0.952$)$ as fewer patients in the combination arm were changed to TC by their oncologists (6.25\%) than in pegfilgrastim alone arm (14.29\%) (Table $2 b$ ).

For the combined therapy cohort other secondary endpoints favored the combination: FN events (Online Resource Table 5) treatment exposure (Online Resource Table 6) and CD34+ stem cell mobilization (Online Resource Table 7). Combined plinabulin $20 \mathrm{mg} / \mathrm{m}^{2}$ and pegfilgrastim $6 \mathrm{mg}$ did not alter EORTCQLQC30 scores compared with pegfilgrastim alone (Online Resource Fig. 6). Reductions in platelet counts were larger with pegfilgrastim $6 \mathrm{mg}$ monotherapy than with any of the plinabulin monotherapy treatments (Online Resource Fig. 7a). In the combined therapy cohort, platelet counts decreased with increasing pegfilgrastim dose (Online Resource Fig. 7b). In correlation with this, the incidence of all grades of thrombocytopenia increased with increasing pegfilgrastim dose (Online Resource Fig. 8). 
Exploratory endpoints also demonstrated the clinical benefit of combination plinabulin $20 \mathrm{mg} / \mathrm{m}^{2}$ and pegfilgrastim $6 \mathrm{mg}$ compared with pegfilgrastim alone, including lower mean DSN (0.69 vs 0.73 days), lower mean duration of Grade 3 and 4 neutropenia (0.9 vs 1.3 days) and incidence ( $56 \%$ vs $86 \%$ ) of Grade 3 and 4 neutropenia, lower incidence of Grade 4 neutropenia (38\% vs 59\%), a higher median ANC nadir ( 1.00 vs 0.46 cells $\times 10^{9} / \mathrm{L}$ ), and less bone pain (score of 0.0 vs 1.6 on Cycle 1 , Day 8 ). An additional exploratory analysis demonstrated the Week 1 ANC protective benefit of plinabulin, including Grade 4 neutropenia incidence in all six arms with plinabulin $(n=93,31.2 \%)$ compared to pegfilgrastim $6 \mathrm{mg}$ $(\mathrm{n}=22,59.1 \%)(P=0.0149)$.

To investigate use of a fixed dose of plinabulin, we performed extensive PK analyses similar to the equivalence modeling for PROTECTIVE1 [9]. The fixed dose plinabulin $40 \mathrm{mg}$ is equivalent to plinabulin $20 \mathrm{mg} / \mathrm{m}^{2}$ (Online Resource Supplemental Material and Online Resource Fig. 9). The RP3D for the next phase of PROTECTIVE-2 clinical trial is plinabulin $40 \mathrm{mg}$ on the day of chemotherapy and pegfilgrastim 6 $\mathrm{mg}$ on the day after chemotherapy.

\subsection{Adverse Events}

In the monotherapy cohort, all patients experienced at least one treatment-emergent adverse event (TEAE) (Table 3a). In the pegfilgrastim $6 \mathrm{mg}$ group, 21 of 22 patients (95.5\%) experienced at least one Adverse Event (AE). The frequency of serious AEs was not substantially different between the plinabulin 20 $\mathrm{mg} / \mathrm{m}^{2}$ cohort (13.3\%) and the pegfilgrastim $6 \mathrm{mg}$ cohort (9.1\%). Two deaths occurred in the monotherapy cohort: one patient in the plinabulin $10 \mathrm{mg} / \mathrm{m}^{2}$ group died of sepsis, and one patient in the plinabulin $30 \mathrm{mg} / \mathrm{m}^{2}$ group died of septic shock. In the combination therapy cohort, all patients experienced at least one TEAE (Table 3b). The RP3D combination arm had lower frequencies of Grade 3 ( $18.8 \%$ vs $31.8 \%$, respectively) and Grade 4 (37.5\% vs $54.5 \%)$ AEs compared with pegfilgrastim alone. Serious AEs were inversely correlated with pegfilgrastim dose, primarily due to more CINrelated AEs. One patient in the plinabulin $20 \mathrm{mg} / \mathrm{m}^{2}$ and pegfilgrastim $3 \mathrm{mg}$ group died of heart failure during the trial. No infections or sepsis, but one hospitalization, occurred in the plinabulin $20 \mathrm{mg} / \mathrm{m}^{2}$ and pegfilgrastim $6 \mathrm{mg}$ group.

Changes in systolic and diastolic blood pressure were not clinically significant; they were transient and of short duration. There were no clinically relevant changes in clinical biochemistry, hematology, or urinalysis parameters in any treatment arm.

\section{Discussion}

Single agent plinabulin protects the ANC in the first week of the chemotherapy cycle, and single agent pegfilgrastim protects the ANC in the second week. This observation led to successfully testing the combination. First, we demonstrated that the monotherapy $20 \mathrm{mg} / \mathrm{m}^{2}$ plinabulin dose performed better than other plinabulin doses but did not provide optimum ANC protection. By protocol amendment, we 
tested the combination of $20 \mathrm{mg} / \mathrm{m}^{2}$ plinabulin dose with de-escalating pegfilgrastim doses and demonstrated that plinabulin $20 \mathrm{mg} / \mathrm{m}^{2}$ on Day 1 with pegfilgrastim $6 \mathrm{mg}$ on Day 2 was best performing. This result was confirmed with detailed pharmacokinetic and pharmacodynamic modeling. We next modeled plinabulin $40 \mathrm{mg}$ as a fixed dose and found PK equivalence to the body surface area-based dose of $20 \mathrm{mg} / \mathrm{m}^{2}$, similar to the result in our previous study [9]. These differences are consistent with in vitro observations of a different mechanism of action for plinabulin compared with G-CSF-derived pegfilgrastim $[8,24]$. On the basis of the shape of the clinical neutrophil recovery curves and the in vitro data, we hypothesize that the protection of hematopoietic stem cells from docetaxel-induced damage explains plinabulin's neutrophil protective effects. The dose and schedule for testing in the Phase 3 portion of PROTECTIVE-2 will be plinabulin $40 \mathrm{mg}$ on Day 1 and pegfilgrastim $6 \mathrm{mg}$ Day 2.

The combination facilitates the delivery of higher relative dose intensity. Maintenance of chemotherapy dose and dose intensity improves cure in several settings. In early-stage breast cancer, dose-dense chemotherapy improves outcomes and reduces complications $[25,26]$. In patients with lymphoma treated with curative intent, dose-dense chemotherapy also improves outcomes in older patients [27]. Maintenance of full-dose chemotherapy with G-CSF support in palliative settings is not currently recommended, as costs are not outweighed by the benefits [28]. With new supportive care agents including G-CSF biosimilars and agents such as plinabulin and trilaciclib with different mechanisms of actions and cost, $[29,30]$, and increases in hospital care costs, the cost-benefit calculus will change. Furthermore, the patient benefit of avoiding dose delay, dose reduction, and dose deferral should be revisited.

Delivery of higher dose-intensity chemotherapy is accompanied by higher chemotherapy complications, including febrile neutropenia (FN) and its sequelae - antibiotic use, unplanned hospitalization, and death. The FN rate for dose dense AC in the initial clinical trial was 3\% [25] but is higher in general use, as indicated from observational studies [31], and is considered high FN-risk (i.e., greater than 20\%) by the NCCN guideline panel [32]. Other two-drug regimens, such as three-week AC (i.e., non-dose dense), are also high FN-risk, and real-world FN rates range as high as $25 \%$ in Asian populations [33]. The two-agent docetaxel cyclophosphamide regimen (TC) is also widely used [34] and is considered by the NCCN panel to be a high neutropenic fever risk. Our results suggest that the FN rates associated with the three-drug combination TAC can by improved with the combination plinabulin and pegfilgrastim, and the two-drug combination TC can also have lower FN risk. The Phase 2 results we report are the basis for the Phase 3 clinical trial, which will test the ability of the combination plinabulin and pegfilgrastim to lower the FN risk, as well as the clinical consequences of FN.

No new toxicities emerged during our trial with combined plinabulin with pegfilgrastim. Hypertension incidence was low and transient during the trial. There was no dosedependent relationship between post plinabulin blood pressure and plinabulin dose, as shown by the PK/PD analysis. Treatment related AEs were of lower severity with the combination compared with single-agent pegfilgrastim. No deaths were considered by the investigators to be related to plinabulin or pegfilgrastim treatments. We did not detect any ANC-related differences in patients by geographic origin, as has been observed for docetaxel [35-37]. 
An unexpected positive finding in our Phase 2 trial was the mitigation of G-CSF-related bone pain with the combination therapy [38-41]. Patients in the pegfilgrastim alone group experienced more bone pain, and more days of bone pain, than did patients taking combined pegfilgrastim and plinabulin. No patients in the RP3D arm experienced 5 or more days of bone pain compared with $4(18 \%)$ of patients taking pegfilgrastim alone. In addition, patients in all plinabulin arms experienced less thrombocytopenia than patients receiving pegfilgrastim, and statistically equivalent quality of life.

\subsection{Limitations}

DSN, when less than 2 days, probably has low predictive value for clinically relevant endpoints such as FN, hospitalization, unplanned care, and death. The small sample sizes in each arm may have yielded an inaccurate DSN for pegfilgrastim (0.73 days) compared with 1.2 to 1.8 days and a relatively low incidence of Grade 4 neutropenia for pegfilgrastim (59.1\%) compared with 83-93\% in larger studies [14, 15]. The DSN estimate drove the trial size determination. Seemingly discordant results on the secondary and exploratory endpoints of febrile neutropenia and $\mathrm{FN}$ clinical sequelae may be a result of the relatively small sample size and relatively small numbers for FN in the control arm. Furthermore, absence of blinding could impact subjective measures, such as patientreported bone pain. We plan to mitigate these potential limitations further in the Phase 3 portion.

\subsection{Conclusions}

Plinabulin recently received breakthrough designation for CIN prevention from the US Food and Drug Administration (FDA) and China National Medical Products Administration (NMPA). Combining plinabulin $20 \mathrm{mg} / \mathrm{m}^{2}$ and pegfilgrastim $6 \mathrm{mg}$ ameliorates neutropenia throughout the chemotherapy cycle, has potentially better $\mathrm{CIN}$ prevention and safety profile than either agent alone, and almost eradicated pegfilgrastiminduced bone pain. The confirmatory Phase 3 portion of PROTECTIVE-2 will test superiority of plinabulin $40 \mathrm{mg}$ and pegfilgrastim $6 \mathrm{mg}$ combination therapy over pegfilgrastim $6 \mathrm{mg}$ alone in earlystage breast cancer patients treated with TAC. The Phase 3 trial excludes patients with bone metastases to allow evaluation of bone pain as an endpoint and has CIN endpoints and formally evaluates quality of life, FN, hospitalization, and infectionrelated complications.

\section{Declarations}

\section{Acknowledgments}

This study was funded by BeyondSpring Pharmaceuticals, Inc. The authors are indebted to the patients who took part in the trial and the staff at the clinical research sites. The authors would like to thank Dr. Lesley Taylor of Alchemy Medical Writing Ltd. for medical writing contributions to an earlier version of this manuscript, which was funded by BeyondSpring Pharmaceuticals, Inc. We also acknowledge the statistical support of Dominic Mitchell of Logimetrix and the contribution of Yvette LeLorier, both of whom were compensated by BeyondSpring Pharmaceuticals, Inc. Additionally, the authors would like to acknowledge that plinabulin achieved $13^{\text {th }} 5$ year innovation grant from the Chinese government. 


\section{Funding}

This study was funded by BeyondSpring Pharmaceuticals, Incorporated. Dr. Blayney reports receiving grants to his institution from BeyondSpring Pharmaceuticals, Incorporated. Additionally, the authors would like to acknowledge that plinabulin achieved $13^{\text {th }} 5$ year innovation grant from the Chinese government.

\section{Competing Interests}

Dr. Blayney reports receiving grants to his institution from BeyondSpring Pharmaceuticals, Incorporated, and travel and lodging support from BeyondSpring Pharmaceuticals, Incorporated during the conduct of the study, grants to Stanford Cancer Institute from Amgen, owns stock in Madora and Artelo Biosciences, and has received consulting fees from Diaichi, Embold Health, Ipsen, Tersera, and Lilly. Dr. Huang reports being an employee and stockholder of BeyondSpring Pharmaceuticals, Incorporated, as well as having involvement in a patent issued for the use of plinabulin in reducing docetaxel-induced neutropenia. Dr. Mohanlal reports being an employee and stockholder of BeyondSpring Pharmaceuticals, Incorporated. Dr. Du is an employee of Wanchun Bulin Pharmaceuticals Limited. Dr. Ette is an employee of Anoxis Corporation. Dr. Ogenstad is an employee of Statogen Consulting. All remaining authors have no relevant financial or non-financial interests to disclose.

\section{Author Contributions}

The academic senior authors (Douglas W. Blayney and Yuan-kai Shi), sponsor Chief Medical Officer (Ramon Mohanlal), and the first author (Douglas W. Blayney) designed the trial with input from other authors. Data were gathered and analyzed by representatives of the sponsor (Douglas W. Blayney, Qingyuan Zhang, Lihua Du, Ene Ette, Stephan Ogenstad, Hryhoriy Adamchuk, Tao Sun, Hongsheng Li, Jifen Feng, Yuan-kai Shi). All authors confirm that the trial complied with the protocol, attest to the accuracy and comprehensiveness of the data, and have (along with their participating institutions) agreements with the sponsor regarding confidentiality of all patient data. The academic first author (Douglas W. Blayney), who had full access to the data, wrote an initial draft of the manuscript. All authors were involved in interpreting, writing, and reviewing subsequent drafts of the manuscript and in making the decision to submit the manuscript for publication. All authors read and approved the final manuscript.

\section{Data Availability}

The datasets generated during and/or analyzed during the current study are not publicly available due to participant privacy concerns but can be accessed from the corresponding author on reasonable request.

\section{Code Availability}

Not applicable

\section{Ethics approval}


This study was performed in line with the principles of the Declaration of Helsinki and the International Council for Harmonisation Good Clinical Practice (GCP) guidelines. The protocol was approved by the relevant Independent Ethics Committee or Institutional Review Board at each site.

\section{Consent to participate}

Informed consent was obtained from all individual participants included in the study.

\section{Consent to publish}

Not applicable

\section{Previous presentations}

Portions of this work have been reported at the American Society of Clinical Oncology (ASCO) Annual Meeting, Chicago, May 31, 2019; 16th St. Gallen International Breast Cancer Conference, Vienna, March 20, 2019; American Society of Clinical Oncology/Society for Immunotherapy of Cancer (ASCO/SITC) Clinical Immuno-Oncology Symposium, San Francisco, March 1, 2019; Annual Meeting of the European Society of Medical Oncology (ESMO), Barcelona, September 27, 2019; ESMO, Madrid virtual), September 19, 2020, Madrid; San Antonio Breast Cancer Symposium, December 8-12, 2020 (virtual), San Antonio.

\section{References}

1. Crawford J, Ozer H, Stoller R, Johnson D, Lyman G, Tabbara I, et al (1991) Reduction by granulocyte colony-stimulating factor of fever and neutropenia induced by chemotherapy in patients with smallcell lung cancer. New England Journal of Medicine 325(3):164-170. https://org/10.1056/NEJM199107183250305

2. Denduluri N, Patt DA, Wang Y, Bhor M, Li X, Favret AM, et al (2015) Dose Delays, Dose Reductions, and Relative Dose Intensity in Patients With Cancer Who Received Adjuvant or Neoadjuvant Chemotherapy in Community Oncology Practices. Journal of the National Comprehensive Cancer Network 13(11):1383-1393. https://org/10.6004/jnccn.2015.0166

3. Holmes FA, Jones SE, O'Shaughnessy J, Vukelja S, George T, Savin M, et al (2002) Comparable efficacy and safety profiles of once-per-cycle pegfilgrastim and daily injection filgrastim in chemotherapy-induced neutropenia: a multicenter dose-finding study in women with breast cancer. Annals of Oncology 13(6):903-909. https://org/10.1093/annonc/mdf130

4. Crawford J, Althaus B, Armitage J, Blayney DW, Cataland S, Dale DC, et al (2005) Myeloid growth factors clinical practice guidelines in oncology. Journal of the National Comprehensive Cancer Network 3(4):540-555. https://org/10.6004/jnccn.2005.0030

5. Becker PS, Griffiths EA, Alwan LM, Bachiashvili K, Brown A, Cool R, et al (2020) NCCN Guidelines Insights: Hematopoietic Growth Factors, Version 1.2020. Journal of the National Comprehensive Cancer Network 18(1):12-22. https://org/10.6004/jnccn.2020.0002 
6. Mita MM, Spear MA, Yee LK, Mita AC, Heath El, Papadopoulos KP, et al (2010) Phase 1 first-in-human trial of the vascular disrupting agent plinabulin(NPI-2358) in patients with solid tumors or lymphomas. Clinical Cancer Research 16(23):5892-5899. https://org/10.1158/1078-0432.CCR-101096

7. Millward M, Mainwaring P, Mita A, Federico K, Lloyd GK, Reddinger N, et al (2012) Phase 1 study of the novel vascular disrupting agent plinabulin (NPI-2358) and docetaxel. Investigational New Drugs 30(3):1065-1073. https://org/10.1007/s10637-011-9642-4

8. Tonra JR, Lloyd GK, Mohanlal R, Huang L (2020) Plinabulin ameliorates neutropenia induced by multiple chemotherapies through a mechanism distinct from G-CSF therapies. Cancer Chemotherapy and Pharmacology 85(2):461-468. https://org/10.1007/s00280-019-03998-w

9. Blayney DW, Zhang Q, Feng J, Zhao Y, Bondarenko I, Vynnychenko I, et al (2020) Efficacy of Plinabulin vs Pegfilgrastim for Prevention of Chemotherapy-Induced Neutropenia in Adults With NonSmall Cell Lung Cancer: A Phase 2 Randomized Clinical Trial. JAMA Oncology 6(11): https://doi.org/10.1001/jamaoncol.2020.4429

10. Martin M, Segui MA, Anton A, Ruiz A, Ramos M, Adrover E, et al (2010) Adjuvant docetaxel for highrisk, node-negative breast cancer. New England Journal of Medicine 363(23):2200-2210. https://org/10.1056/NEJMoa0910320

11. Nabholtz JM, Mackey JR, Smylie M, Paterson A, Noel DR, Al-Tweigeri T, et al (2001) Phase II study of docetaxel, doxorubicin, and cyclophosphamide as first-line chemotherapy for metastatic breast cancer. Journal of Clinical Oncology 19(2):314-321. https://org/10.1200/JC0.2001.19.2.314

12. Holmes FA, O'Shaughnessy JA, Vukelja S, Jones SE, Shogan J, Savin M, et al (2002) Blinded, randomized, multicenter study to evaluate single administration pegfilgrastim once per cycle versus daily filgrastim as an adjunct to chemotherapy in patients with high-risk stage II or stage III/IV breast cancer. Journal of Clinial Oncology 20(3):727-731. https://org/10.1200/JC0.2002.20.3.727

13. Blackwell K, Semiglazov V, Krasnozhon D, Davidenko I, Nelyubina L, Nakov R, et al (2015) Comparison of EP2006, a filgrastim biosimilar, to the reference: a phase III, randomized, double-blind clinical study in the prevention of severe neutropenia in patients with breast cancer receiving myelosuppressive chemotherapy. Annals of Oncology 26(9):1948-1953. https://org/10.1093/annonc/mdv281

14. Schwartzberg LS, Lal LS, Balu S, Campbell K, Brekke L, Elliott C, et al (2018) Incidence of febrile neutropenia during chemotherapy among patients with nonmyeloid cancer receiving filgrastim vs a filgrastim biosimilar. Clinicoeconomics and Outcomes Research 10:493-500. https://org/10.2147/CEOR.S168298

15. Waller CF, Tiessen RG, Lawrence TE, Shaw A, Liu MS, Sharma R, et al (2018) A pharmacokinetics and pharmacodynamics equivalence trial of the proposed pegfilgrastim biosimilar, MYL-1401H, versus reference pegfilgrastim. Journal of Cancer Research and Clinical Oncology 144(6):1087-1095. https://org/10.1007/s00432-018-2643-3 
16. Glaspy JA, O'Connor PG, Tang H, Finck B (2017) Randomized, single-blind, crossover study to assess the pharmacokinetic and pharmacodynamic bioequivalence of CHS-1701 to pegfilgrastim in healthy subjects. Journal of Clinical Oncology 35(15_suppl):21693-e.

https://org/10.1200/JC0.2017.35.15_suppl.e21693

17. Lee J, Lee JE, Kim Z, Han SW, Hur SM, Kim SY, et al (2018) Pegfilgrastim for primary prophylaxis of febrile neutropenia in breast cancer patients undergoing TAC chemotherapy. Annals of Surgical Treatment and Research 94(5):223-228. https://org/10.4174/astr.2018.94.5.223

18. Masuda N, Tokuda Y, Nakamura S, Shimazaki R, Ito Y, Tamura K (2015) Dose response of pegfilgrastim in Japanese breast cancer patients receiving six cycles of docetaxel, doxorubicin, and cyclophosphamide therapy: a randomized controlled trial. Supportive Care in Cancer 23(10):28912898. https://org/10.1007/s00520-015-2654-4

19. Cleeland CS, Ryan KM (1994) Pain assessment: global use of the Brief Pain Inventory. Annals of the Academy of Medicine Singapore 23(2):129-138. PMID: 8080219

20. Cleeland CS. (2009) The Brief Pain Inventory User Guide. Houston, Texas: MD Anderson Cancer Center; 2009. https://www.mdanderson.org/documents/Departments-and-Divisions/SymptomResearch/BPI_UserGuide.pdf

21. Bedard G, Zeng L, Zhang L, Lauzon N, Holden L, Tsao M, et al (2014) Minimal important differences in the EORTC QLQ-C30 in patients with advanced cancer. Asia-Pacific Journal of Clinical Oncology 10(2):109-117. https://org/10.1111/ajco.12070

22. Phillips R, Gandhi M, Cheung YB, Findlay MP, Win KM, Hai HH, et al (2015) Summary scores captured changes in subjects' QoL as measured by the multiple scales of the EORTC QLQ-C30. Journal of Clinical Epidemiology 68(8):895-902. https://org/10.1016/j.jclinepi.2015.02.011

23. Group EQoL. The EORTC QLQ-C30 (2002) Manuals, Reference Values and Bibliography Brussels, Blegium: EORTC Quality of Life Unit. https://www.eortc.org/app/uploads/sites/2/2018/02/reference_values_manual2008.pdf

24. La Salla G, Olieric N, Sharma A, Viti F, de Asis Balaguer Perez F, Huang L, et al (2019) Structure, thermodynamics, and kinetics of plinabulin binding to two tubulin isotypes. Chem 5(11):2969-2986. https://doi.org/10.1016/j.chempr.2019.08.022

25. Citron ML, Berry DA, Cirrincione C, Hudis C, Winer EP, Gradishar WJ, et al (2003) Randomized trial of dose-dense versus conventionally scheduled and sequential versus concurrent combination chemotherapy as postoperative adjuvant treatment of node-positive primary breast cancer: first report of Intergroup Trial C9741/Cancer and Leukemia Group B Trial 9741. Journal of Clinical Oncology 21(8):1431-1439. https://org/10.1200/JC0.2003.09.081

26. Early Breast Cancer Trialists' Collaborative Group (2019) Increasing the dose intensity of chemotherapy by more frequent administration or sequential scheduling: a patient-level metaanalysis of 37298 women with early breast cancer in 26 randomised trials. The Lancet 393(10179):1440-1452. https://org/10.1016/S0140-6736(18)33137-4 
27. Pfreundschuh M, Trumper L, Kloess M, Schmits R, Feller AC, Rube C, et al (2004) Two-weekly or 3weekly CHOP chemotherapy with or without etoposide for the treatment of elderly patients with aggressive lymphomas: results of the NHL-B2 trial of the DSHNHL. Blood 104(3):634-641. https://org/10.1182/blood-2003-06-2095

28. Schnipper LE, Smith TJ, Raghavan D, Blayney DW, Ganz PA, Mulvey TM, et al (2012) American Society of Clinical Oncology identifies five key opportunities to improve care and reduce costs: the top five list for oncology. Journal of Clinical Oncology 30(14):1715-1724. https://org/10.1200/JC0.2012.42.8375

29. Tan AR, Wright GS, Thummala AR, Danso MA, Popovic L, Pluard TJ, et al (2019) Trilaciclib plus chemotherapy versus chemotherapy alone in patients with metastatic triple-negative breast cancer: a multicentre, randomised, open-label, phase 2 trial. The Lancet Oncology 20(11):1587-601. https://org/10.1016/S1470-2045(19)30616-3

30. Weiss JM, Csoszi T, Maglakelidze M, Hoyer RJ, Beck JT, Domine Gomez M, et al (2019) Myelopreservation with the CDK4/6 inhibitor trilaciclib in patients with small-cell lung cancer receiving first-line chemotherapy: a phase $\mathrm{lb} /$ randomized phase II trial. Annals of Oncology 30(10):1613-1621. https://org/10.1093/annonc/mdz278

31. Truong J, Lee EK, Trudeau ME, Chan KKW (2016) Interpreting febrile neutropenia rates from randomized, controlled trials for consideration of primary prophylaxis in the real world: a systematic review and meta-analysis. Annals of Oncology 27(4):608-618. https://org/10.1093/annonc/mdv619

32. Crawford J, Becker PS, Armitage JO, Blayney DW, Chavez J, Curtin P, et al (2017) Myeloid Growth Factors, Version 2.2017, NCCN Clinical Practice Guidelines in Oncology. Journal of the National Comprehensive Cancer Network 15(12):1520-41. https://org/10.6004/jnccn.2017.0175

33. Kim CG, Sohn J, Chon H, Kim JH, Heo SJ, Cho H, et al (2016) Incidence of Febrile Neutropenia in Korean Female Breast Cancer Patients Receiving Preoperative or Postoperative Doxorubicin/Cyclophosphamide Followed by Docetaxel Chemotherapy. Journal of Breast Cancer 19(1):76-82. https://org/10.4048/jbc.2016.19.1.76

34. Jones SE, Savin MA, Holmes FA, O'Shaughnessy JA, Blum JL, Vukelja S, et al (2006) Phase III trial comparing doxorubicin plus cyclophosphamide with docetaxel plus cyclophosphamide as adjuvant therapy for operable breast cancer. Journal of Clinical Oncol 24(34):5381-5387. https://org/10.1200/JC0.2006.06.5391

35. Kenmotsu H, Tanigawara Y (2015) Pharmacokinetics, dynamics and toxicity of docetaxel: Why the Japanese dose differs from the Western dose. Cancer Science 106(5):497-504. https://org/10.1111/cas.12647

36. Yano R, Konno A, Watanabe K, Tsukamoto H, Kayano Y, Ohnaka H, et al (2013) Pharmacoethnicity of docetaxel-induced severe neutropenia: integrated analysis of published phase II and III trials. International Journal of Clinical Oncology 18(1):96-104. https://org/10.1007/s10147-011-0349-5

37. Yip AY, Chow LW (2006) Clinical experience with docetaxel for Chinese breast cancer patients: hematological toxicity profiles. Breast Cancer 13(2):192-196. https://org/10.2325/jbcs.13.192 
38. Kubista E, Glaspy J, Holmes FA, Green MD, Hackett J, Neumann T, et al (2003) Bone pain associated with once-per-cycle pegfilgrastim is similar to daily filgrastim in patients with breast cancer. Clinical Breast Cancer 3(6):391-398. https://org/10.3816/cbc.2003.n.003

39. Moore DC, Pellegrino AE (2017) Pegfilgrastim-Induced Bone Pain: A Review on Incidence, Risk Factors, and Evidence-Based Management. Annals of Pharmacotherapy 51(9):797-803. https://org/10.1177/1060028017706373

40. Pawloski PA, Larsen M, Thoresen A, Giordana MD (2016) Pegfilgrastim use and bone pain: a cohort study of community-based cancer patients. Journal of Oncology Pharmacy Practice 22(3):423-429. https://org/10.1177/1078155215585188

41. Lambertini M, Del Mastro L, Bellodi A, Pronzato P (2014) The five "Ws" for bone pain due to the administration of granulocyte-colony stimulating factors (G-CSFs). Critical Reviews in Oncology/Hematology 89(1):112-128. https://org/10.1016/j.critrevonc.2013.08.006

\section{Tables}

Table 1. Statistical analysis of duration of severe neutropenia during Cycle 1 for patients taking A) monotherapy and B) combined therapy (Intent-to-Treat population)

\section{A)}

\begin{tabular}{|c|c|c|c|c|}
\hline & $\begin{array}{l}\text { Pegfilgrastim } \\
6 \mathrm{mg} \\
(\mathrm{n}=22)\end{array}$ & $\begin{array}{l}\text { Plinabulin } 10 \\
\mathrm{mg} / \mathrm{m}^{2} \\
(\mathrm{n}=15)\end{array}$ & $\begin{array}{l}\text { Plinabulin } 20 \\
\mathrm{mg} / \mathrm{m}^{2} \\
(\mathrm{n}=15)\end{array}$ & $\begin{array}{l}\text { Plinabulin } 30 \\
\mathrm{mg} / \mathrm{m}^{2} \\
(\mathrm{n}=12)\end{array}$ \\
\hline $\begin{array}{l}\text { Mean (SD) Days of Severe } \\
\text { Neutropenia }\end{array}$ & $0.73(0.70)$ & $1.33(0.90)$ & $1.13(1.06)$ & $2.83(1.75)$ \\
\hline & & \multicolumn{3}{|c|}{ Treatment Difference versus Pegfilgrastim 6 mg } \\
\hline Difference in the mean & & 0.61 & 0.41 & 2.11 \\
\hline $95 \% \mathrm{Cl}$ & & $(-1.631,2.843)$ & $(-2.087,2.899)$ & $(-1.589,5.801)$ \\
\hline$P$ value & & 0.2977 & 0.3748 & 0.1320 \\
\hline
\end{tabular}

$\mathrm{Cl}$, confidence interval.

95\% $\mathrm{Cl}$ and two-sided $P$-values were calculated by using Poisson Regression model.

B) 


\begin{tabular}{|c|c|c|c|c|}
\hline & $\begin{array}{l}\text { Pegfilgrastim } \\
6 \mathrm{mg} \\
(\mathrm{n}=22)\end{array}$ & $\begin{array}{l}\text { Plinabulin } 20 \\
\mathrm{mg} / \mathrm{m}^{2} \\
+ \\
\text { Pegfilgrastim } \\
1.5 \mathrm{mg} \\
(\mathrm{n}=14)\end{array}$ & $\begin{array}{l}\text { Plinabulin } 20 \\
\mathrm{mg} / \mathrm{m}^{2} \\
+ \\
\text { Pegfilgrastim } \\
3 \mathrm{mg} \\
(\mathrm{n}=21)\end{array}$ & $\begin{array}{l}\text { Plinabulin } 20 \\
\mathrm{mg} / \mathrm{m}^{2} \\
+ \\
\text { Pegfilgrastim } \\
6 \mathrm{mg} \\
(\mathrm{n}=16)\end{array}$ \\
\hline $\begin{array}{l}\text { Mean (SD) Days of Severe } \\
\text { Neutropenia }\end{array}$ & $0.73(0.70)$ & $1.36(1.45)$ & $1.05(1.16)$ & $0.69(1.01)$ \\
\hline & & \multicolumn{3}{|c|}{ Treatment Difference versus Pegfilgrastim 6 mg } \\
\hline Difference in the mean & & 0.63 & 0.32 & -0.04 \\
\hline $95 \% \mathrm{Cl}$ & & $(-2.523,3.782)$ & $\begin{array}{l}(-2.339 \\
2.980)\end{array}$ & $\begin{array}{l}(-2.458 \\
2.379)\end{array}$ \\
\hline$P$ value & & 0.3477 & 0.4067 & 0.5129 \\
\hline \multicolumn{5}{|l|}{ Relevant CIN efficacy parameters } \\
\hline Grade 4 neutropenia (cycle 1 ) & $59 \%$ & & & $38 \%$ \\
\hline $\begin{array}{l}\text { Grade } 3 \text { and } 4 \text { neutropenia } \\
\text { (cycle 1) }\end{array}$ & $86 \%$ & & & $56 \%$ \\
\hline $\begin{array}{l}\text { Duration of grade } 3 \text { and } 4 \\
\text { neutropenia (cycle } 1)\end{array}$ & 1.3 day & & & 0.9 day \\
\hline Median ANC Nadir ( $\times 10^{9}$ cell/L) & 0.46 & & & 1.0 \\
\hline
\end{tabular}

$\mathrm{Cl}$, confidence interval.

95\% $\mathrm{Cl}$ and two-sided $P$-values were calculated by using Poisson Regression model.

Table 2. Patients in the control (Pegfilgrastim $6 \mathrm{mg}$ ) and the RP3D (Pegfilgrastim $6 \mathrm{mg}$ and Plinabulin 20 $\mathrm{mg} / \mathrm{m}^{2}$ ) arms (A) who received $>85 \%$ of the specified TAC chemotherapy, and (B) relative dose intensity for each treatment arm
A) 


\begin{tabular}{|lllc|}
\hline & $\begin{array}{l}\text { Number of patients who } \\
\text { received }>85 \% \text { TAC }(\%)\end{array}$ & $\begin{array}{l}\text { Number of patients who } \\
\text { received } \leq 85 \% \text { TAC }\end{array}$ & Total \\
\hline Pegfilgrastim $6 \mathrm{mg}$ & $18(82)$ & 4 & 22 \\
\hline $\begin{array}{l}\text { Pegfilgrastim } 6 \mathrm{mg} \text { and } \\
\text { Plinabulin } 20 \mathrm{mg} / \mathrm{m}^{2}\end{array}$ & $16(100)$ & 0 & 16 \\
\hline$P$ value* & 0.0752 & & \\
\hline
\end{tabular}

SD, standard deviation; TAC, docetaxel, doxorubicin, and cyclophosphamide.

*Probability of the difference occurring by chance, according to the Cochran-Mantel-Haenszel Statistic.

B)

Treatment Pegfilgrastim $6 \mathrm{mg}$ Plinabulin $20 \mathrm{mg} / \mathrm{m}^{2}+$ Pegfilgrastim $6 \mathrm{mg}$
regimen

\begin{tabular}{lll}
\hline$N^{a}$ & 22 & 16 \\
\hline Overall RDI ${ }^{\mathrm{b}}$ TAC & & \\
\hline Mean (SD) & 0.952 & 0.998 \\
& $(0.10)$ & $(0.03)$ \\
\hline$P$ value & 0.0985 &
\end{tabular}

N/A, not applicable; RDI, relative dose intensity; SD, standard deviation; TAC, docetaxel, doxorubicin, and cyclophosphamide.

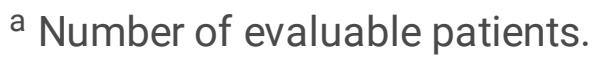

${ }^{\mathrm{b}} \mathrm{RDI}$ for TAC is computed for each patient by taking the individual sum of the of the administered drug (in $\mathrm{mg} / \mathrm{m}^{2}$ ) over 4 cycles and dividing each sum by four times the specified dose for each drug (i.e. docetaxel $75 \times 4=300 \mathrm{mg} / \mathrm{m}^{2}$, doxorubicin $50 \times 4=200 \mathrm{mg} / \mathrm{m}^{2}$, cyclophosphamide $500 \times 4=2000$ $\mathrm{mg} / \mathrm{m}^{2}$ ). Each averaged dose administered is summed, and this sum is divided by three (i.e., the number of drugs in TAC) to derive an average dose administered. (Note that for patients who received TC in cycles 2-4, as specified in the protocol to be determined by the clinical judgment of their treating investigator, the dose administered of doxorubicin is set to "0" for cycles 2-3 as appropriate from the data). The treatment duration is computed as the number of days between Cycle 1 Day 1 and the Cycle 3 Day 1 plus 21 days and converted to weeks by dividing by 7 . The RDI for each patient is the quotient of the average dose administered divided by the treatment duration. The relative dose intensity for each treatment arm is the sum of the average dose intensity for all patient in the arm divided by the number of patients in each arm. 
Table 3. Summary of treatment-emergent adverse events affecting $\geq 10 \%$ patients in any treatment group in the A) monotherapy and B) combined therapy cohorts (Safety population)
A) 


\begin{tabular}{|c|c|c|c|c|}
\hline \multirow[t]{2}{*}{$\begin{array}{c}\text { System Organ Class } \\
\text { Preferred Term }\end{array}$} & $\begin{array}{l}\text { Pegfilgrastim } 6 \\
\text { mg } \\
(N=22)\end{array}$ & $\begin{array}{l}\text { Plinabulin } \\
10 \\
\mathrm{mg} / \mathrm{m}^{2} \\
(N=15)\end{array}$ & $\begin{array}{l}\text { Plinabulin } \\
20 \\
\mathrm{mg} / \mathrm{m}^{2} \\
(N=15)\end{array}$ & $\begin{array}{l}\text { Plinabulin } \\
30 \\
\mathrm{mg} / \mathrm{m}^{2} \\
(N=12)\end{array}$ \\
\hline & \multicolumn{4}{|c|}{ Number of patients (\%) } \\
\hline Any TEAEs & $21(95.5)$ & $15(100)$ & $15(100)$ & $12(100)$ \\
\hline Blood and lymphatic system disorders & $16(72.7)$ & $10(66.7)$ & $11(73.3)$ & $10(83.3)$ \\
\hline Anaemia & $5(22.7)$ & $2(13.3)$ & $7(46.7)$ & $8(66.7)$ \\
\hline Febrile neutropenia & $1(4.5)$ & 0 & $3(20.0)$ & $3(25.0)$ \\
\hline Leukopenia & $9(40.9)$ & $4(26.7)$ & $1(6.7)$ & 0 \\
\hline Neutropenia & $12(54.5)$ & $10(66.7)$ & $6(40.0)$ & $1(8.3)$ \\
\hline Thrombocytopenia & $3(13.6)$ & 0 & 0 & $1(8.3)$ \\
\hline Gastrointestinal disorders & $16(72.7)$ & $6(40.0)$ & $7(46.7)$ & $11(91.7)$ \\
\hline Abdominal distension & 0 & $1(6.7)$ & 0 & $4(33.3)$ \\
\hline Constipation & $2(9.1)$ & $1(6.7)$ & $2(13.3)$ & $2(16.7)$ \\
\hline Diarrhoea & $7(31.8)$ & $2(13.3)$ & $1(6.7)$ & $6(50.0)$ \\
\hline Nausea & $12(54.5)$ & $3(20.0)$ & $5(33.3)$ & $7(58.3)$ \\
\hline Vomiting & 0 & $2(13.3)$ & $2(13.3)$ & $6(50.0)$ \\
\hline $\begin{array}{l}\text { General disorders and administration site } \\
\text { conditions }\end{array}$ & $10(45.5)$ & $2(13.3)$ & $4(26.7)$ & $5(41.7)$ \\
\hline Fatigue & $6(27.3)$ & 0 & 0 & 0 \\
\hline Malaise & $3(13.6)$ & $1(6.7)$ & $3(20.0)$ & $3(25.0)$ \\
\hline Pyrexia & 0 & $2(13.3)$ & 0 & 0 \\
\hline Hepatobiliary disorders & 0 & $1(6.7)$ & $2(13.3)$ & 0 \\
\hline Hepatic steatosis & 0 & 0 & $2(13.3)$ & 0 \\
\hline Infections and infestations & 0 & $4(26.7)$ & 0 & $3(25.0)$ \\
\hline Anal abscess & 0 & $2(13.3)$ & 0 & 0 \\
\hline Influenza & 0 & $2(13.3)$ & 0 & 0 \\
\hline Investigations & $15(68.2)$ & $11(73.3)$ & $15(100)$ & $12(100)$ \\
\hline Alanine aminotransferase & $3(13.6)$ & $1(6.7)$ & $2(13.3)$ & $1(8.3)$ \\
\hline Aspartate aminotransferase increased & $\begin{array}{l}3(13.6) \\
\text { Page 20/26 }\end{array}$ & $2(13.3)$ & $1(6.7)$ & $1(8.3)$ \\
\hline
\end{tabular}




\begin{tabular}{|lllll|}
\hline Gamma-glutamyl transferase increased & 0 & $2(13.3)$ & $1(6.7)$ & 0 \\
\hline Haemoglobin decreased & 0 & 0 & $2(13.3)$ & 0 \\
\hline Neutrophil count decreased & $9(40.9)$ & $9(60.0)$ & $13(86.7)$ & $11(91.7)$ \\
\hline Platelet count decreased & $7(31.8)$ & $2(13.3)$ & $4(26.7)$ & $5(41.7)$ \\
\hline Weight decreased & $2(9.1)$ & $1(6.7)$ & $2(13.3)$ & $1(8.3)$ \\
\hline White blood cell count decreased & $11(50.0)$ & $11(73.3)$ & $15(100)$ & $12(100)$ \\
\hline Metabolism and nutrition disorders & $7(31.8)$ & $3(20.0)$ & $7(46.7)$ & $4(33.3)$ \\
\hline Decreased appetite & $5(22.7)$ & $1(6.7)$ & $2(13.3)$ & 0 \\
\hline Hyperglycaemia & $2(9.1)$ & $2(13.3)$ & $2(13.3)$ & $3(25.0)$ \\
\hline $\begin{array}{l}\text { Musculoskeletal and connective tissue } \\
\text { disorders }\end{array}$ & $6(27.3)$ & $2(13.3)$ & $2(13.3)$ & $3(25.0)$ \\
\hline Bone pain & $5(22.7)$ & $1(6.7)$ & $2(13.3)$ & $2(16.7)$ \\
\hline $\begin{array}{l}\text { Respiratory, thoracic and mediastinal } \\
\text { disorders }\end{array}$ & $2(9.1)$ & $3(20.0)$ & $1(6.7)$ & $1(8.3)$ \\
\hline Dyspnoea & $1(4.5)$ & $2(13.3)$ & $1(6.7)$ & $1(8.3)$ \\
\hline Skin and subcutaneous tissue disorders & $14(63.6)$ & $4(26.7)$ & $8(53.3)$ & $4(33.3)$ \\
\hline $\begin{array}{l}\text { Alopecia } \\
\text { Vascular disorders }\end{array}$ & $13(59.1)$ & $4(26.7)$ & $8(53.3)$ & $4(33.3)$ \\
\hline Hypertension & 0 & $1(6.7)$ & $1(6.7)$ & $2(16.7)$ \\
\hline
\end{tabular}

TEAE, treatment emergent adverse event.

B) 


\begin{tabular}{|c|c|c|c|c|}
\hline $\begin{array}{c}\text { System Organ Class } \\
\text { Preferred Term }\end{array}$ & $\begin{array}{l}\text { Pegfilgrastim } \\
(6 \mathrm{mg}) \\
(\mathrm{N}=22)\end{array}$ & $\begin{array}{l}\text { Plinabulin } \\
20 \mathrm{mg} / \mathrm{m}^{2}+ \\
\text { Pegfilgrastim } \\
1.5 \mathrm{mg} \\
(N=14)\end{array}$ & $\begin{array}{l}\text { Plinabulin } \\
20 \mathrm{mg} / \mathrm{m}^{2}+ \\
\text { Pegfilgrastim } 3 \\
\mathrm{mg} \\
(\mathrm{N}=21)\end{array}$ & $\begin{array}{l}\text { Plinabulin } \\
20 \mathrm{mg} / \mathrm{m}^{2}+ \\
\text { Pegfilgrastim } 6 \\
\mathrm{mg} \\
(N=16)\end{array}$ \\
\hline & \multicolumn{4}{|c|}{ Number of patients (\%) } \\
\hline Any TEAEs & $21(95.5)$ & $14(100)$ & $21(100)$ & $16(100)$ \\
\hline $\begin{array}{l}\text { Blood and lymphatic } \\
\text { system disorders }\end{array}$ & $16(72.7)$ & $7(50.0)$ & $11(52.4)$ & $9(56.3)$ \\
\hline Anaemia & $5(22.7)$ & $6(42.9)$ & $9(42.9)$ & $8(50.0)$ \\
\hline Febrile neutropenia & $1(4.5)$ & $2(14.3)$ & $1(4.8)$ & $1(6.3)$ \\
\hline Leukopenia & $9(40.9)$ & 0 & $4(19.0)$ & $1(6.3)$ \\
\hline Neutropenia & $12(54.5)$ & $1(7.1)$ & $6(28.6)$ & $1(6.3)$ \\
\hline Thrombocytopenia & $3(13.6)$ & $1(7.1)$ & $5(23.8)$ & $1(6.3)$ \\
\hline Cardiac disorders & $1(4.5)$ & $2(14.3)$ & $2(9.5)$ & $1(6.3)$ \\
\hline Gastrointestinal disorders & $16(72.7)$ & $6(42.9)$ & $18(85.7)$ & $10(62.5)$ \\
\hline Abdominal distension & 0 & $2(14.3)$ & $1(4.8)$ & $1(6.3)$ \\
\hline Constipation & $2(9.1)$ & $2(14.3)$ & $3(14.3)$ & $1(6.3)$ \\
\hline Diarrhoea & 7 (31.8) & $4(28.6)$ & $10(47.6)$ & $6(37.5)$ \\
\hline Nausea & $12(54.5)$ & $3(21.4)$ & $9(42.9)$ & $6(37.5)$ \\
\hline Vomiting & 0 & $1(7.1)$ & $3(14.3)$ & $1(6.3)$ \\
\hline $\begin{array}{l}\text { General disorders and } \\
\text { administration site } \\
\text { conditions }\end{array}$ & $10(45.5)$ & $4(28.6)$ & $11(52.4)$ & $1(6.3)$ \\
\hline Fatigue & $6(27.3)$ & $2(14.3)$ & $4(19.0)$ & 0 \\
\hline Malaise & $3(13.6)$ & $1(7.1)$ & $5(23.8)$ & $1(6.3)$ \\
\hline Infections and infestations & 0 & $3(21.4)$ & $4(19.0)$ & $1(6.3)$ \\
\hline Lung infection & 0 & $2(14.3)$ & $1(4.8)$ & 0 \\
\hline Investigations & $15(68.2)$ & $13(92.9)$ & $18(85.7)$ & $15(93.8)$ \\
\hline Alanine aminotransferase & $3(13.6)$ & $6(42.9)$ & $8(38.1)$ & $1(6.3)$ \\
\hline $\begin{array}{l}\text { Aspartate } \\
\text { aminotransferase } \\
\text { increased }\end{array}$ & $3(13.6)$ & $5(35.7)$ & $5(23.8)$ & $1(6.3)$ \\
\hline Neutrophil count & $9(40.9)$ & $10(71.4)$ & $11(52.4)$ & $12(75.0)$ \\
\hline
\end{tabular}




\begin{tabular}{|c|c|c|c|c|}
\hline Platelet count decreased & 7 (31.8) & $2(14.3)$ & $4(19.0)$ & $12(75.0)$ \\
\hline $\begin{array}{l}\text { White blood cell count } \\
\text { decreased }\end{array}$ & $11(50.0)$ & $10(71.4)$ & 13 (61.9) & $14(87.5)$ \\
\hline $\begin{array}{l}\text { Metabolism and nutrition } \\
\text { disorders }\end{array}$ & $7(31.8)$ & $11(78.6)$ & $9(42.9)$ & $3(18.8)$ \\
\hline Decreased appetite & $5(22.7)$ & $3(21.4)$ & $4(19.0)$ & 0 \\
\hline Hyperglycaemia & $2(9.1)$ & $8(57.1)$ & $5(23.8)$ & $2(12.5)$ \\
\hline Hypokalaemia & 0 & $2(14.3)$ & 0 & $2(12.5)$ \\
\hline $\begin{array}{l}\text { Musculoskeletal and } \\
\text { connective tissue disorders }\end{array}$ & $6(27.3)$ & $5(35.7)$ & $8(38.1)$ & $1(6.3)$ \\
\hline Arthralgia & 0 & $1(7.1)$ & $3(14.3)$ & 0 \\
\hline Bone pain & $5(22.7)$ & $5(35.7)$ & 7 (33.3) & $1(6.3)$ \\
\hline Nervous system disorders & $4(18.2)$ & $2(14.3)$ & $5(23.8)$ & 0 \\
\hline Dysgeusia & $1(4.5)$ & $2(14.3)$ & 0 & 0 \\
\hline $\begin{array}{l}\text { Respiratory, thoracic, and } \\
\text { mediastinal disorders }\end{array}$ & $2(9.1)$ & $1(7.1)$ & $4(19.0)$ & $1(6.3)$ \\
\hline $\begin{array}{l}\text { Skin and subcutaneous } \\
\text { tissue disorders }\end{array}$ & $14(63.6)$ & $5(35.7)$ & $10(47.6)$ & $8(50.0)$ \\
\hline Alopecia & $13(59.1)$ & $3(21.4)$ & $8(38.1)$ & $8(50.0)$ \\
\hline Vascular disorders & 0 & $2(14.3)$ & $2(9.5)$ & $1(6.3)$ \\
\hline
\end{tabular}

TEAE, treatment-emergent adverse event.

\section{Figures}




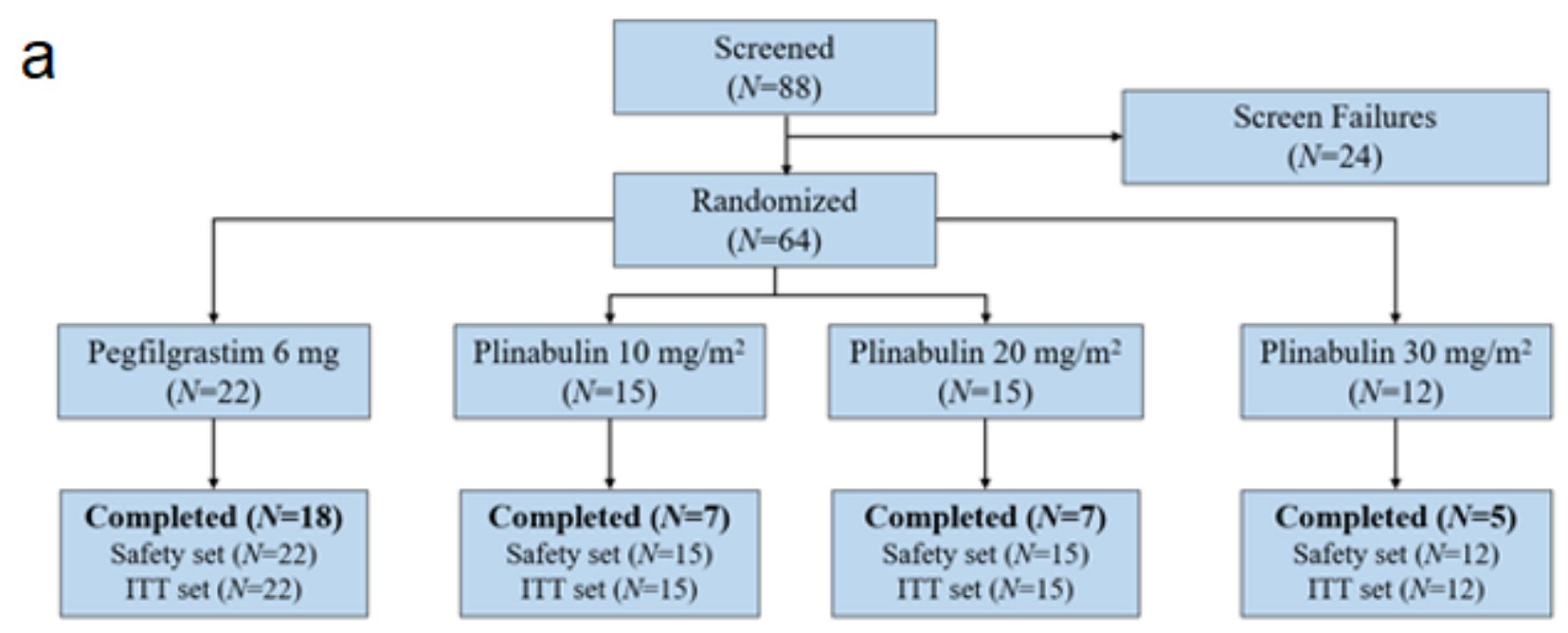

b

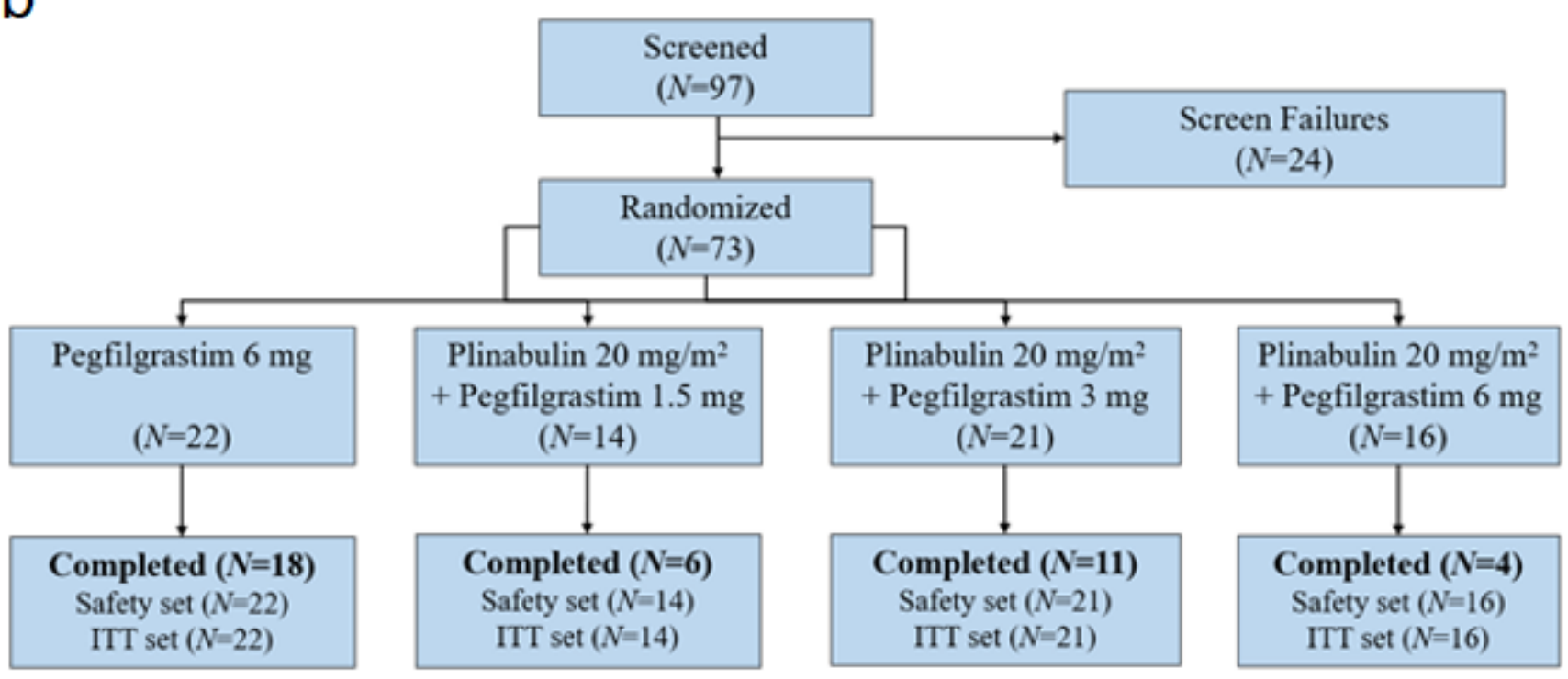

\section{Figure 1}

Disposition of patients in Study BPI-2358-106 The figure summarizes the disposition of patients enrolled in the study. One hundred fifteen patients were treated: 42 in the monotherapy (a) and 51 in the combination therapy (b) cohorts; 22 patients who were concurrently randomized to pegfilgrastim $6 \mathrm{mg}$ were included in both cohorts for comparison purposes. The number of patients at each step (screening, screen failure, randomization, treatment, completion) is indicated with an $\mathrm{N}$ in each colored box. Arrows indicate the flow of patients through the study. ITT, intent-to-treat. 
a
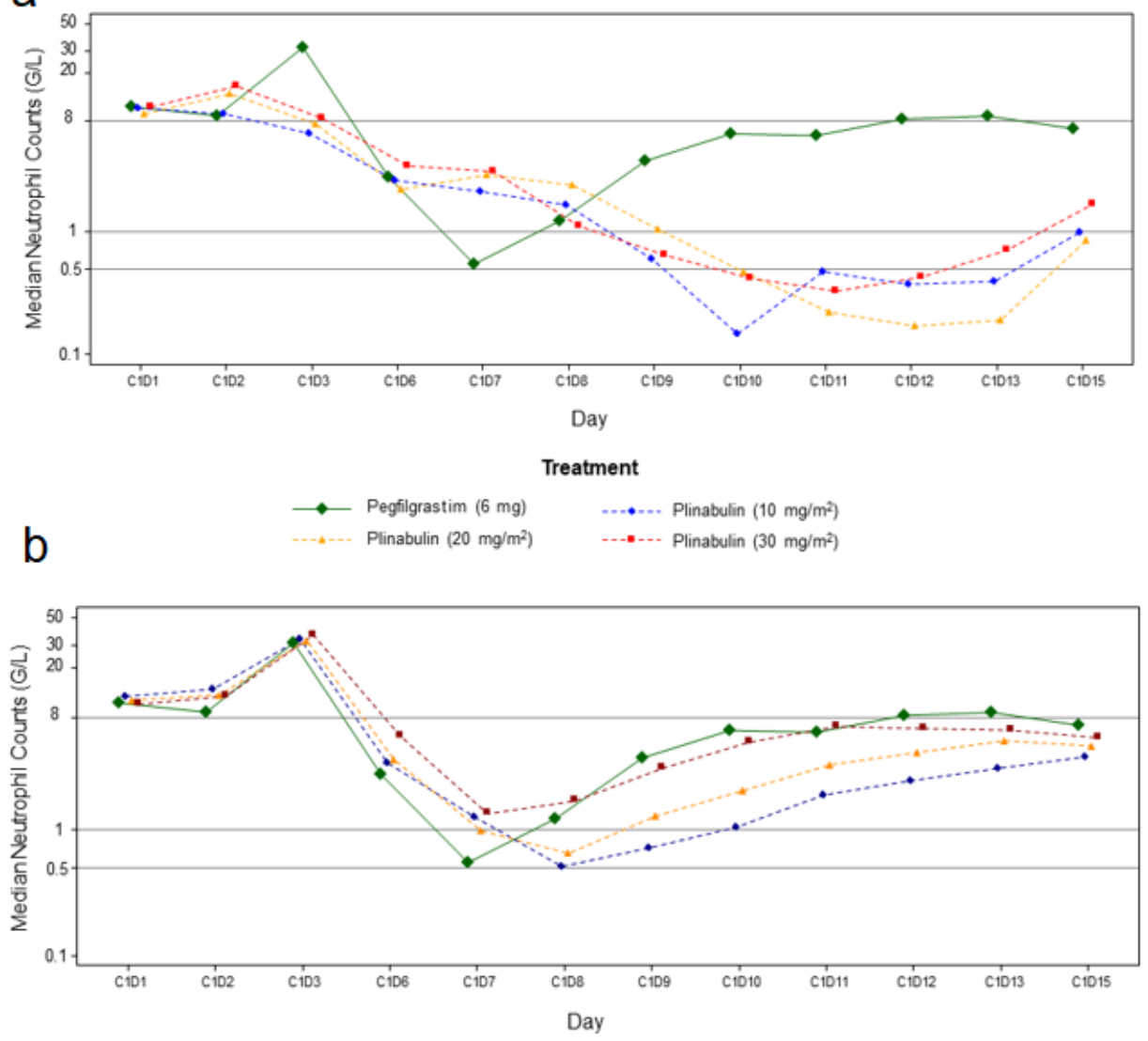

Treatment

$\longrightarrow$ Pegfilgrastim $(6 \mathrm{mg}) \quad \ldots \ldots$ Plinabulin $\left(20 \mathrm{mg} / \mathrm{m}^{2}\right)+$ Pegfilgrastim $(1.5 \mathrm{mg})$

...... Plinabulin $\left(20 \mathrm{mg} / \mathrm{m}^{2}\right)+$ Pegfilgrastim $(3 \mathrm{mg}) \quad \ldots$ Plinabulin $\left(20 \mathrm{mg} / \mathrm{m}^{2}\right)+$ Pegfilgrastim $(6 \mathrm{mg})$

C

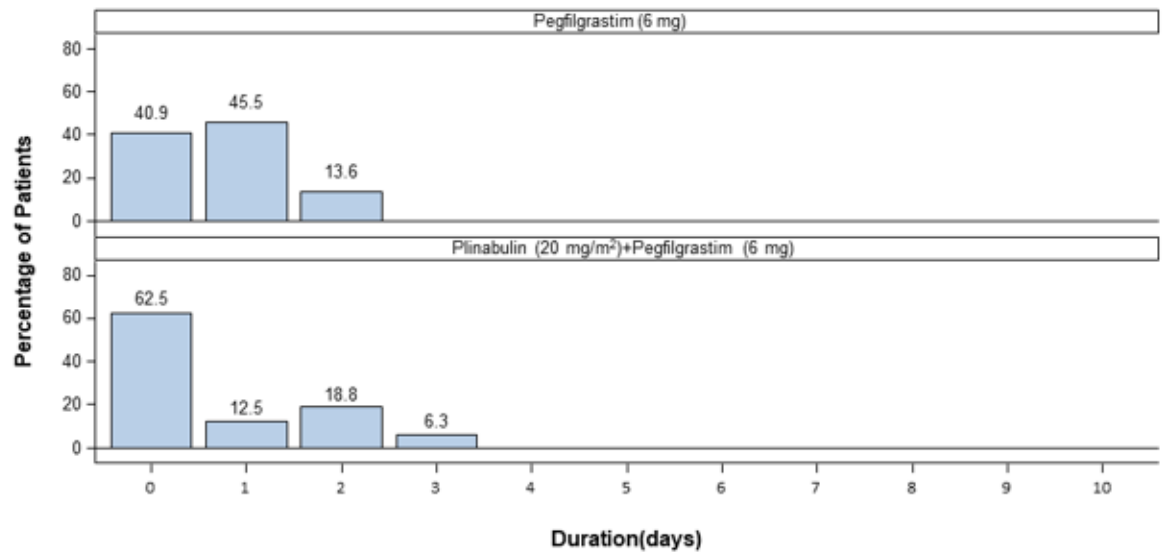

Figure 2

Outcomes of patients in Study BPI-2358-106 The figure summarizes the outcomes of patients enrolled in the study. ANC recovery curves for (a) the monotherapy cohort, (b) the combination therapy cohort, (c) distribution of DSN, and (d) days of bone pain among patients who received the recommended phase 3 dose in chemotherapy Cycle 1. For (a) and (b), the x-axis indicates the day (D) of chemotherapy cycle 1 (C1), the $y$-axis indicates the median neutrophil count (G/L). For (a), colors indicate the cohorts as 
follows: green, pegfilgrastim $6 \mathrm{mg}$; blue, plinabulin $10 \mathrm{mg} / \mathrm{m}^{2}$; orange, plinabulin $20 \mathrm{mg} / \mathrm{m}^{2}$; red, plinabulin $30 \mathrm{mg} / \mathrm{m}^{2}$. For (b), colors indicate the cohorts as follows: green, pegfilgrastim $6 \mathrm{mg}$; blue, plinabulin $20 \mathrm{mg} / \mathrm{m}^{2}$ plus pegfilgrastim $1.5 \mathrm{mg}$; orange, plinabulin $20 \mathrm{mg} / \mathrm{m}^{2}$ plus pegfilgrastim $3 \mathrm{mg}$; red, plinabulin $20 \mathrm{mg} / \mathrm{m}^{2}$ plus pegfilgrastim $6 \mathrm{mg}$. The lower horizontal lines indicate Grade $4\left(0.5 \times 10^{9}\right.$ cells/Liter) and Grade $3\left(1.0 \times 10^{9}\right.$ cells/Liter). In (a), single agent plinabulin did not keep the ANC above Grade 4 toxicity, though these curves demonstrate that the characteristics of the ANC recovery curves are different. In (b), the plinabulin $20 \mathrm{mg} / \mathrm{m} 2$ combined with pegfilgrastim $6 \mathrm{mg}$ (red dotted line) keeps the mean ANC above Grade 3 toxicity throughout the chemotherapy course, compared with the comparison pegfilgrastim $6 \mathrm{mg}$ (green solid line). For (c), the x-axis indicates the number of days of severe neutropenia (Grade 4), the $y$-axis indicates the percentage of patients. The upper graph is the pegfilgrastim $6 \mathrm{mg}$ (monotherapy) cohort, the lower graph is the $20 \mathrm{mg} / \mathrm{m}^{2}$ plus pegfilgrastim $6 \mathrm{mg}$ (combination therapy) cohort. The combination therapy cohort had more days without severe neutropenia. For (d), the x-axis (top line) indicates the number of days of bone pain, the x-axis (bottom line) indicates the $P$ value, and the $y$-axis indicates the percentage of patients. Colors indicate the cohorts as follows: green, pegfilgrastim $6 \mathrm{mg}$; red, plinabulin $20 \mathrm{mg} / \mathrm{m}^{2}$ plus pegfilgrastim $6 \mathrm{mg}$. The monotherapy cohort experienced more days of bone pain. ANC, absolute neutrophil count; DSN, days of severe neutropenia.

\section{Supplementary Files}

This is a list of supplementary files associated with this preprint. Click to download.

- BlayneyetalBPI106P2SupplementalMaterial.pdf 